\title{
Avaliação da influência do sexo e das linhagens de camundongo NIH e BALB/cAn no teste de ganho de peso da vacina DTP
}

\author{
Evaluation of the influence of sex and of NIH and BALB/CAn mouse \\ strains in the mouse weight gain test of DTP vaccine
}

\author{
Roseli Maria Domingos',* iD \\ Reginaldo Assad Miller' iD \\ Alexandre Pinto Corrado" (iD \\ Helena Pereira da Silva Zamith' iD
}

\section{RESUMO}

Introdução: 0 teste de ganho de peso em camundongos (TGPC) para a determinação da toxicidade da vacina pertussis de células inteiras (VPCl) é essencial para aprovar o emprego da vacina adsorvida contra a difteria, o tétano e a pertussis (DTP) nos programas de vacinação infantil. Objetivo: Avaliar a influência do sexo e das linhagens de camundongo (NIH e BALB/c An) no TGPC da VPCl de referência, da toxina pertussis (TP) e de 36 amostras de vacinas DTP. Método: Dez animais de cada sexo e linhagem foram pesados e, em seguida, inoculados intraperitonealmente com $0,5 \mathrm{~mL} /$ camundongo da VPCI de referência, de TP (0,25-2,0 $\mu \mathrm{g} / \mathrm{animal})$ ou de vacinas DTP. Grupos-controle para VPCl e TP foram inoculados com PBS e para vacinas DTP empregou-se o cloreto de sódio $0,9 \%$ com 100 ppm de timerosal. 0 teste é satisfatório se não ocorrerem mortes, se o ganho de peso médio (GPM) dos animais inoculados no $3^{\circ}$ dia for superior ao inicial e no $7^{\circ}$ dia o GPM for igual ou maior que $60 \%$ do controle. Os resultados do TGPC foram avaliados pelos critérios em vigência e pelo proposto no $7^{\circ}$ dia, no qual o limite inferior do intervalo de confiança de 95\% do GPM seja igual ou maior que $60 \%$ do controle. Resultados: A VPCI de referência foi satisfatória em fêmeas NIH e BALB/cAn e insatisfatória em machos de ambas as linhagens considerando-se ambos os critérios. O TGPC em ambas as linhagens e sexos revelou baixa sensibilidade na detecção do efeito da TP isolada (0,25-2,0 $\mu \mathrm{g} /$ camundongo). As vacinas DTP foram satisfatórias em camundongos NIH de ambos os sexos e em fêmeas BALB/cAn, porém o resultado foi insatisfatório para $14,0 \%$ das vacinas DTP em machos BALB/cAn por ambos os critérios. Conclusões: O TGPC de vacinas DTP em camundongos fêmeas de ambas as linhagens deve ser considerado, pois evidenciou-se que fêmeas NIH e BALB/cAn são adequadas para a realização do TGPC. A adoção do critério proposto no $7^{\circ}$ dia deve ser estimulado por aumentar a sensibilidade e precisão do TGPC.

PALAVRAS-CHAVE: Teste de Ganho de Peso em Camundongos; Vacina Adsorvida Difteria, Tétano e Pertussis; Toxina Pertussis; Camundongos NIH; Camundongos BALB/cAn

\section{ABSTRACT}

Introduction: The mouse weight gain test (MWGT) for determination of toxicity of whole-cell pertussis vaccine (WCPV) is essential to approve the use of diphtheria, tetanus and whole cell pertussis (DTwP) vaccine (adsorbed) in childhood vaccination programs. Objective: To evaluate the influence of sex and of the mouse strains (NIH and BALB/CAn) on MWGT of the reference WCPV, pertussis toxin (PT) and 36 samples of DTwP vaccines. Method: Ten animals of each sex and strain were weighed, and then inoculated intraperitoneally with $0.5 \mathrm{~mL} /$ mouse of the reference WCPV, of PT (0.25-2.0 $\mu \mathrm{g} / \mathrm{animal})$, or DTwP vaccines. Control groups for WCPV and PT were inoculated with PBS and for DTwP vaccines $0.9 \%$ sodium chloride was used with $100 \mathrm{ppm}$ of thimerosal. The test is satisfactory if there are no deaths, if the average weight gain (AWG) of the inoculated animals on the 3rd day is higher than the initial one and if on the 7th day the AWG is 
equal to or greater than $60 \%$ of the control. The MWGT results were evaluated by the current and by the proposed criteria on the 7 th day, in which the lower limit of the $95 \%$ confidence interval of the AWG was equal to or greater than $60 \%$ of the control. Results: The reference WCPV was satisfactory in NIH and BALB/CAn females and unsatisfactory in males of both strains considering both criteria. The MWGT in both sexes and strains revealed low sensitivity in detecting the effect of isolated PT (0.25-2.0 $\mu \mathrm{g} / \mathrm{mouse})$. DTwP vaccines were satisfactory in NIH mice of both sexes and in BALB/CAn females, but the result was unsatisfactory for $14.0 \%$ of DTwP vaccines in BALB/CAn males by both criteria. Conclusions: The MWGT of DTWP vaccines in female mice of both strains should be considered as it has been shown that NIH and BALB/CAn females are suitable for the MWGT. The adoption of the criterion proposed in the 7th day should be stimulated as it increases the sensitivity and precision of the MWGT.

KEYWORDS: Mouse Weight Gain Test; Diphtheria, Tetanus and Whole Cell Pertussis Vaccine (Adsorbed); Pertussis Toxin; NIH Mice; BALB/cAn Mice

\section{INTRODUÇÃOO}

A coqueluche ou pertussis é uma doença infecciosa aguda transmissível causada pela bactéria Bordetella pertussis, que compromete especificamente o aparelho respiratório (traqueia e brônquios). Esta doença é uma causa importante de morbidade e mortalidade de crianças em todo o mundo e continua sendo uma preocupação de saúde pública, apesar da alta cobertura vacinal ${ }^{1}$. No Brasil, a partir de setembro de 2012, seguindo as orientações da Organização Mundial da Saúde (OMS) de aumentar a cobertura vacinal com combinação de vacinas em uma mesma aplicação, foi introduzida no calendário básico de rotina a vacina adsorvida pentavalente contra a difteria, o tétano, a pertussis, a hepatite $B(\mathrm{HB})$ e Haemophillus influenzae tipo b (conjugada) (Hib). A vacina pentavalente (DTP/HB/Hib) é aplicada aos $2,4 \mathrm{e}$ 6 meses de idade, enquanto os reforços e/ou complementação de esquema em crianças a partir de 1 ano são realizadas com a vacina adsorvida tríplice contra a difteria, tétano e pertussis $(\mathrm{DTP})^{2}$. A vacina DTP/HB/Hib pode causar vários eventos adversos, geralmente entre as primeiras $48 \mathrm{a} 72 \mathrm{~h}$ que se seguem à sua aplicação $(0,5 \mathrm{~mL})$ por via intramuscular, sendo o componente pertussis o principal responsável pela ocorrência das reações indesejáveis ${ }^{3}$. A partir de estudo clínico realizado no Brasil com as vacinas brasileiras DTP/HB/Hib e tetravalente (DTP-Hib), esta utilizada no país de 2002 a 2012, constatou-se semelhante reatogenicidade quanto à ocorrência de reações adversas para ambas as vacinas ${ }^{2}$ e também para a vacina DTP adsorvida de células inteiras descrita por Cody et al. ${ }^{4}$. As reações locais (rubor, calor, endurecimento e edema, acompanhados ou não de dor) e sistêmicas (febre baixa a moderada) são frequentes após aplicação de vacinas DTP ou combinadas, podendo ocorrer em até $50 \%$ dos casos. A frequência de ocorrência de irritabilidade é de $2,6 \%$ a $85,5 \%$, de sonolência prolongada até $32,0 \%$, de anorexia entre $2,0 \%$ a $26,5 \%$ e de vômitos entre $1,7 \%$ a $7,8 \%^{2}$. No entanto, a maioria dos eventos adversos observados tem evolução limitada, com recuperação completa, não constituindo contraindicações para a inoculação de doses subsequentes da vacina ${ }^{2}$. Evento neurológico grave, como convulsão, geralmente acompanhado de febre alta, é de incidência rara e relatado por Cody et al. ${ }^{4}$, ocorrendo na frequência de $1 / 1.750$ doses aplicadas da vacina DTP.

Frente à ocorrência de possíveis efeitos adversos e para comprovação da sua eficácia, como ocorre com as demais vacinas, testes biológicos são realizados com a vacina adsorvida DTP visando não só a determinação da sua potência, como também da sua toxicidade 5 . Estes testes são indispensáveis para aprovar o emprego das vacinas adsorvidas combinadas DTP/HB/Hib, DTP-Hib ou DTP nos programas de vacinação infantil, nos quais as vacinas são aplicadas. Segundo a Farmacopeia Brasileira, no tocante ao componente pertussis, os testes de segurança biológica preconizados no controle da qualidade da vacina DTP para avaliação da toxicidade são: o teste para detecção de toxina termolábil ou dermonecrótica e o teste de ganho de peso em camundongos (TGPC) $)^{5}$. Na sexta edição da Farmacopeia Brasileira, recentemente publicada, além da monografia da vacina adsorvida DTP, constam as monografias das vacinas adsorvidas combinadas, DTP-Hib, DTP/HB/Hib, e da vacina pentavalente contra difteria, tétano, pertussis, poliomielite 1 , 2 e 3 (inativada) e Haemophillus influenzae tipo b (conjugada). Nesta mesma publicação, para todas essas vacinas deverá ser realizado, como teste de segurança biológica, o TGPC para o produto final ${ }^{6}$. O TGPC é também preconizado pelas Farmacopeias Europeia ${ }^{7}$ e Britânica ${ }^{8}$ e OMS $^{9}$ para as vacinas DTP e DTP adsorvidas combinadas.

O TGPC é considerado um teste geral, não específico, que mede a toxicidade geral de vacina pertussis de células inteiras (VPCl), uma vez que, as toxinas produzidas por células de B. pertussis, presentes na vacina sob a forma inativada, podem induzir perda de peso em camundongos jovens ${ }^{9}$. Correlação dos resultados do TGPC com as reações adversas em crianças tem sido relatada $10,11,12,13$.

Dentre as toxinas produzidas por $B$. pertussis, a toxina pertussis (TP), exotoxina presente na $\mathrm{VPCl}$, é considerada a principal responsável pelas manifestações sistêmicas da coqueluche, bem como pelos efeitos adversos observados no decorrer da imunização pela vacina DTP ${ }^{14}$. Os principais efeitos biológicos da TP, em pacientes e em animais de laboratório infectados por $B$. pertussis, incluem: indução da linfocitose, sensibilização à histamina e hipoglicemia/insulinemia. Tais efeitos são devidos à ativação das células $B$ das ilhotas pancreáticas ${ }^{15}$. 0 outro componente da VPCI, a endotoxina, lipopolissacarídio (LPS) associado à membrana externa da $B$. pertussis, está claramente correlacionada ao quadro de febre em crianças ${ }^{16}$. 
As mudanças em peso correspondem ao conhecido curso do TGPC, no qual os animais inoculados perdem peso nas primeiras $24 \mathrm{~h}$ quando comparados ao controle, mas, após três dias, já mostram um aumento significativamente maior do que no início do teste. Após sete dias, os animais inoculados alcançam os animais-controle e seus pesos excedem significativamente os requeridos $60 \%$ do peso-controle ${ }^{17}$.

Estudo interlaboratorial conduzido em 1991, com seis diferentes vacinas DTP e com a participação de 14 laboratórios de diferentes países, mostrou que o TGPC, apesar do uso de camundongos-controle, apresentou pouca reprodutibilidade. Os resultados mostraram uma variação interlaboratorial de aproximadamente $30 \%$ (o ganho de peso no $7^{\circ}$ dia ficou na faixa de $60 \%$ a $160 \%$ ), principalmente atribuída ao fato de que diferentes linhagens de camundongos foram usadas pelos laboratórios $^{18}$. Este estudo mostrou também que a variabilidade intralaboratorial foi alta. Algumas preparações que dificilmente alcançaram o requerimento para $60 \%$ de ganho de peso no primeiro teste, uma semana mais tarde, no segundo teste ocasionaram um ganho de peso acima de $100 \%{ }^{18}$. A principal conclusão deste estudo foi que, além da constatação de alta variabilidade intra e interlaboratorial dos resultados do TGPC para vacinas DTP, confirmou-se que sob as mesmas condições de teste, a linhagem de camundongo influencia o resultado do teste.

O objetivo do trabalho foi avaliar a influência do sexo e de duas linhagens de camundongos (NIH e BALB/CAn) nos resultados do TGPC da VPCI de referência, da TP e de 36 amostras de vacinas DTP produzidas no Brasil.

\section{MÉTODO}

Camundongos das linhagens NIH (outbred) e BALB/cAn (inbred) de ambos os sexos, com peso entre $14 \mathrm{e} 16 \mathrm{~g}$, foram aclimatados no mínimo por $24 \mathrm{~h}$ antes do início do TGPC da VPCI de referência, da TP e das vacinas DTP. Os animais foram fornecidos pelo Instituto de Ciência e Tecnologia em Biomodelos (ICTB) da Fundação Oswaldo Cruz (Fiocruz) e mantidos em caixas de polipropileno com tampa de aço inoxidável em estantes ventiladas, à temperatura ambiental de $20^{\circ} \mathrm{C} \pm 2{ }^{\circ} \mathrm{C}$, umidade relativa de cerca de $70 \%$ e ciclo claro-escuro de $12 \mathrm{~h}$, com acesso livre à água e à ração (Nuvilab). A solicitação de licença de projeto foi obtida junto a Comissão de Ética no Uso de Animais (CEUA/Fiocruz) sob o número L-010/05.

O monitoramento sanitário dos camundongos realizado pelo ICTB, segundo as recomendações da Federation of European Laboratory Animal Science Associations (FELASA), envolveu a pesquisa de três grupos de micro-organismos (vírus, bactérias, micoplasma) e parasitos específicos ${ }^{19}$. Foram monitorados os seguintes vírus: da ectromélia, da coriomeningite linfocitária (LCM), da hepatite murina (MHV), poliomavírus, pneumovírus (PVM), reovírus tipo 3 (REO-3), Sendai e da encefalomielite murina de Theiler (TMEV). As bactérias e micoplasma pesquisados foram: Bordetella bronchiseptica, Cillia-assoc resp. Bacillus, Citrobacter rodetium, Klebsiella pneumoniae, Mycoplasma pulmonis, Pasteurella spp, Pseudomonas spp, Salmonella spp, Staphylococcus haemolyticus, Staphylococcus aureus, Streptococcus beta hemolítico (grupo D) e Streptococcus pneumoniae. Dentre os parasitos monitorados, incluem-se: pulgas, ácaros, piolhos, Syphacia spp, Aspiculuris tetraptera, Rodentolepis nana, tricomonídeos, Spironucleus muris, Giardia muris e Entamoeba spp.

A VPCI de referência utilizada foi o Terceiro Padrão Internacional para Vacina Pertussis fornecido pelo National Institute for Biological Standards and Control (NIBSC), código 66/303, com uma potência de $46 \mathrm{UI}$ por ampola, sob a forma liofilizada. Antes do seu uso, foi diluída em $8 \mathrm{~mL}$ de solução salina tamponada de fosfato (PBS) para se obter a mesma concentração como nas vacinas no TGPC de meia dose humana $/ 0,5 \mathrm{~mL}$.

A TP de referência (NIBSC: 90/518) reconstituída com PBS foi inoculada por via intraperitoneal (ip) no volume de $0,5 \mathrm{~mL} / \mathrm{ani}$ mal em quatro doses $(0,25 ; 0,5 ; 1,0$ e $2,0 \mu \mathrm{g} /$ camundongo $)$.

Foram utilizadas trinta e seis amostras de vacinas DTP de um único produtor nacional. Conforme descrito na bula da vacina DTP, cada dose $(0,5 \mathrm{~mL})$ contém antígenos diftérico e tetânico suficientes para indução de $2 \mathrm{UI}$ de antitoxina em cobaia, $4 \mathrm{UI}$ de antígeno pertussis (coqueluche), hidróxido de alumínio (até $1,25 \mathrm{mg}$ em alumínio), timerosal até $20 \mathrm{mg}$ e solução fisiológica tamponada $\mathrm{pH} 6,4$ em quantidade suficiente para $0,5 \mathrm{~mL}$. Antes da inoculação por via ip no volume de $0,5 \mathrm{~mL} /$ camundongo, a vacina foi diluída na proporção de 1:1 com solução fisiológica de cloreto de sódio $0,9 \%$. As 36 amostras de vacinas DTP foram testadas simultaneamente, numa mesma linhagem e sexo, em paralelo com o respectivo grupo-controle.

O TGPC foi realizado de acordo com o descrito na Farmacopeia Brasileira ${ }^{5,6}$. Antes do TGPC, os animais foram pesados, marcados individualmente e separados aleatoriamente em grupos de dez. Seus pesos iniciais individuais foram registrados. Cada grupo teste foi inoculado por via ip, com volume de $0,5 \mathrm{~mL} /$ camundongo de $\mathrm{VPCl}$ de referência, de TP e de vacinas DTP preparadas como descrito acima. Grupos-controles foram inoculados por via ip com $0,5 \mathrm{~mL} /$ camundongo de solução fisiológica contendo 100 ppm de timerosal (controle da vacina DTP), e dois outros grupos foram inoculados por via ip com 0,5 mL de PBS (controles da VPCI de referência e de TP). Os animais foram observados diariamente durante o período do teste. Os pesos dos animais foram registrados três e sete dias após a inoculação da VPCI, das vacinas DTP e da TP e de seus respectivos controles. Para a amostra ser considerada satisfatória, não devem ocorrer mortes de animais no período de sete dias do TGPC; no $3^{\circ}$ dia, o peso total do grupo inoculado com a VPCI, a DTP ou a TP não pode ser menor que seu peso total inicial; no $7^{\circ}$ dia, o ganho de peso médio (GPM) dos grupos-teste não pode ser menor que $60 \%$ do GPM dos respectivos grupos-controles e o limite inferior $\left(L_{i}\right)$ do intervalo de confiança de 95\% (IC95\%) do GPM dos grupos-teste deve ser igual ou maior a $60 \%$ do GPM dos animais do grupo-controle, como critério proposto por Domingos ${ }^{20}$. 
Na avaliação do efeito da VPCI de referência no TGPC, utilizou-se o teste $\mathrm{t}$ de Student não pareado monocaudal ao nível de significância de $p=0,05$, precedido do teste de Kolmogorov-Smirnov para verificação da normalidade.

No estudo do efeito das quatro doses de TP em relação ao controle (PBS), utilizou-se a análise de variância (ANOVA one way) precedido pelo teste para verificação da normalidade (Kolmogorov-Smirnov) e do teste para verificação da homocedasticidade (teste de Bartlett). Uma vez detectada uma diferença estatisticamente significativa $(p<0,05)$ pela ANOVA one way empregou-se os testes de comparações múltiplas de Tukey e de Dunnett.

O programa computacional GraphPad Prism ${ }^{\circledR} 5.0$ foi empregado na análise estatística dos dados.

\section{RESULTADOS}

Avaliação do ganho de peso dos camundongos dos grupos-controle (PBS) fêmeas e machos de ambas as linhagens no teste de ganho de peso em camundongos da vacina pertussis de células inteiras de referência

No TGPC da VPCI de referência, não houve perda de peso dos animais-controle, fêmeas e machos de ambas as linhagens, três e sete dias após inoculação ip de PBS, quando comparado ao peso inicial. Logo o TGPC da VPCI de referência foi considerado válido. Os dados de ganho de peso dos animais seguiram uma distribuição normal e são mostrados na Figura 1, como GPM \pm erro-padrão da média (EPM).

A Figura 1 mostra que, três dias após a inoculação com PBS, os GPM das fêmeas-controle, de ambas as linhagens, não foram significativamente diferentes $(p>0,05)$ pelo teste $t$ de Student, porém, no período de sete dias, as fêmeas NIH mostraram GPM ligeiramente superior ao das fêmeas BALB/cAn ( $p=0,0473$ ). Após o $3^{\circ}$ e $7^{\circ}$ dias, o GPM dos machos-controle BALB/cAn foi cerca de 1,6 vezes inferior $(p<0,001)$ ao GPM dos machos $\mathrm{NIH}$.

Teste de ganho de peso em camundongos da vacina pertussis de células inteiras de referência

O TGPC da VPCl de referência (NIBSC: 66/303) foi satisfatório em camundongos fêmeas de ambas as linhagens e em machos da linhagem $\mathrm{NIH}$, porém insatisfatório em BALB/cAn macho (Tabela). $O$ peso total dos animais no $3^{\circ}$ dia foi superior ao peso total inicial para todos os grupos em ambos os sexos e linhagens. No $7^{\circ}$ dia, o percentual de GPM de todos os grupos foi superior a $60 \%$ em relação ao do grupo-controle PBS, com exceção do BALB/cAn macho, com percentual inferior a $60 \%(57,9 \%)$. Não houve ocorrência de mortes no período de sete dias do teste. A VPCI de referência foi também insatisfatória em NIH machos, ao se considerar como critério de aprovação no $7^{\circ}$ dia, o Li do IC95\% para a percentagem de ganho de peso igual ou superior a $60 \%$ em relação ao do grupo-controle PBS.

A partir destes resultados, os camundongos fêmeas de ambas as linhagens, pelos critérios vigente e proposto, seriam os mais apropriados do que os camundongos machos BALB/CAn para a realização do TGPC. O TGPC da VPCl de referência em NIH machos foi satisfatório pelo critério vigente, mas seria insatisfatório pelo critério proposto. De acordo com a OMS 9 , o TGPC com a VPCI de referência pode ser empregado na seleção da linhagem de camundongos mais apropriada no TGPC devendo apresentar resultado satisfatório.

Teste de ganho de peso em camundongos da toxina pertussis (NIBSC: 90/518)

O TGPC da TP foi válido, pois, no grupo-controle, não ocorreu perda de peso no $3^{\circ}$ e $7^{\circ}$ dias após inoculação do PBS. $\operatorname{ATP}(0,25$ a $2,0 \mu \mathrm{g} /$ camundongo $)$ não causou mortes de animais

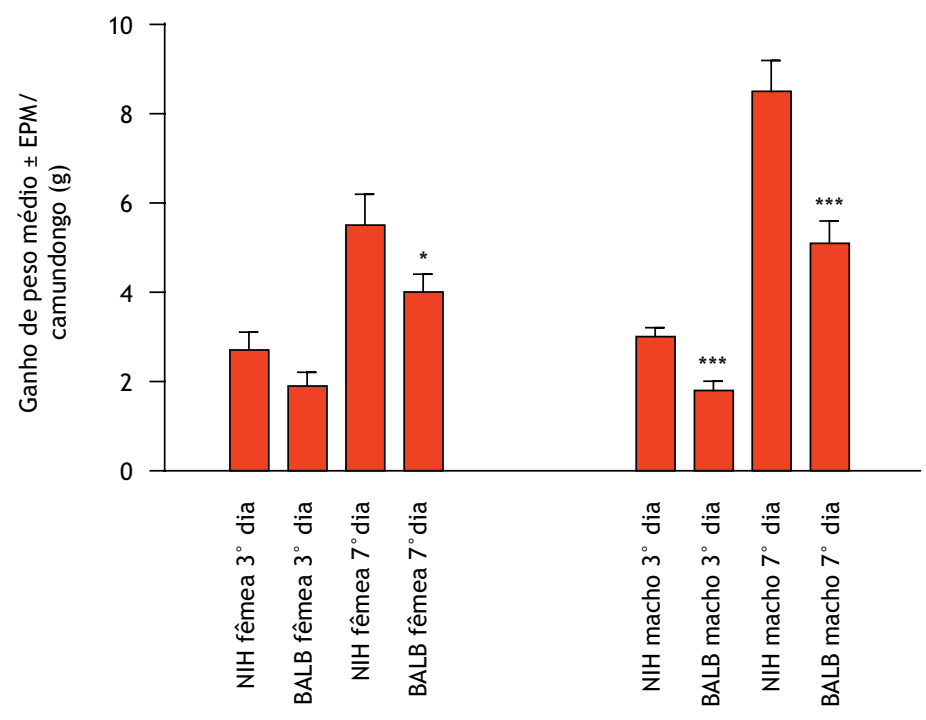

Fonte: Elaborada pelos autores, 2019.

Barras indicam erro-padrão da média (EPM) do ganho de peso médio (g) de 10 animais.

* diferença significativa $(\mathrm{p}<0,05)$; ${ }^{* * *}$ diferença extremamente significativa $(\mathrm{p}<0,001)$ entre as duas linhagens do mesmo sexo pelo teste $t$ de Student.

Figura 1. Ganho de peso dos animais-controle, NIH e BALB/CAn de ambos os sexos, empregados no teste de ganho de peso de camundongos da vacina pertussis de referência (NIBSC: 66/303), três e sete dias após inoculação intraperitoneal $(0,5 \mathrm{~mL})$ de PBS. 
Tabela. Teste de ganho de peso em camundongos da vacina pertussis de células inteiras de referência (NIBSC: 66/303) em camundongos fêmeas e machos das linhagens NIH e BALB/cAn.

\begin{tabular}{|c|c|c|c|c|c|c|c|}
\hline \multicolumn{2}{|c|}{ Ganho de peso $(\mathrm{g})^{1}\left(3^{\circ} \mathrm{dia}\right)$} & \multicolumn{2}{|c|}{$\%$ de ganho de peso ${ }^{2}\left(7^{\circ} \mathrm{dia}\right)$} & \multicolumn{2}{|c|}{ Ganho de peso $(\mathrm{g})^{1}\left(3^{\circ} \mathrm{dia}\right)$} & \multicolumn{2}{|c|}{$\%$ de ganho de peso ${ }^{2}\left(7^{\circ} \mathrm{dia}\right)$} \\
\hline $\begin{array}{c}\text { NIH } \\
\text { fêmea }\end{array}$ & $\begin{array}{c}\text { BALB } \\
\text { fêmea }\end{array}$ & $\begin{array}{c}\text { NIH } \\
\text { fêmea }\end{array}$ & $\begin{array}{c}\text { BALB } \\
\text { fêmea }\end{array}$ & $\begin{array}{c}\mathrm{NIH} \\
\text { macho }\end{array}$ & $\begin{array}{c}\text { BALB } \\
\text { macho }\end{array}$ & $\begin{array}{c}\text { NIH } \\
\text { macho }\end{array}$ & $\begin{array}{c}\text { BALB } \\
\text { macho }\end{array}$ \\
\hline 3,1 & 1,2 & 143,6 & 112,5 & 1,0 & 1,0 & 72,1 & 82,7 \\
\hline 0,5 & 1,0 & 92,7 & 102,5 & 4,0 & 1,8 & 103,5 & 69,2 \\
\hline 2,0 & 0,3 & 116,4 & 87,5 & 1,7 & 0,8 & 94,2 & 80,8 \\
\hline 0,5 & 0,4 & 70,9 & 35,0 & 1,1 & $-0,4$ & 69,8 & 7,7 \\
\hline 1,5 & 0,6 & 116,4 & 77,5 & 1,1 & 0,5 & 65,1 & 44,2 \\
\hline 3,7 & 1,4 & 134,5 & 100,0 & 0,9 & 0,9 & 55,8 & 105,8 \\
\hline 2,0 & 1,1 & 107,3 & 75,0 & 0,9 & 0,7 & 60,5 & 57,7 \\
\hline 1,7 & 0,6 & 112,7 & 65,0 & 1,1 & 1,0 & 50,0 & 59,6 \\
\hline 0,2 & 2,0 & 87,3 & 90,0 & 1,0 & 0,8 & 59,3 & 46,2 \\
\hline 3,7 & 0,4 & 120,0 & 55,0 & 1,9 & $-0,3$ & 108,1 & 25,0 \\
\hline \multicolumn{8}{|c|}{ Média e intervalo de confiança $95 \%$} \\
\hline $\begin{array}{c}1,9 \\
(0,9-2,8)\end{array}$ & $\begin{array}{c}0,9 \\
(0,5-1,3)\end{array}$ & $\begin{array}{c}110,2 \\
(94,6-125,8)\end{array}$ & $\begin{array}{c}80,0 \\
(63,1-96,9)\end{array}$ & $\begin{array}{c}1,5 \\
(0,8-2,1)\end{array}$ & $\begin{array}{c}0,7 \\
(0,2-1,1)\end{array}$ & $\begin{array}{c}73,8 \\
(59,0-88,6)\end{array}$ & $\begin{array}{c}57,9 \\
(37,2-78,5)\end{array}$ \\
\hline \multicolumn{8}{|c|}{ Média e erro-padrão da média } \\
\hline $1,9 \pm 0,4$ & $0,9 \pm 0,2$ & $110,2 \pm 6,9$ & $80,0 \pm 7,5$ & $1,5 \pm 0,3$ & $0,7 \pm 0,2$ & $73,8 \pm 6,5$ & $57,9 \pm 9,1$ \\
\hline
\end{tabular}

Fonte: Elaborada pelos autores, 2019.

${ }^{1}$ Ganho de peso em relação ao peso inicial; ${ }^{2}$ Percentagem de ganho de peso em relação ao grupo-controle PBS.

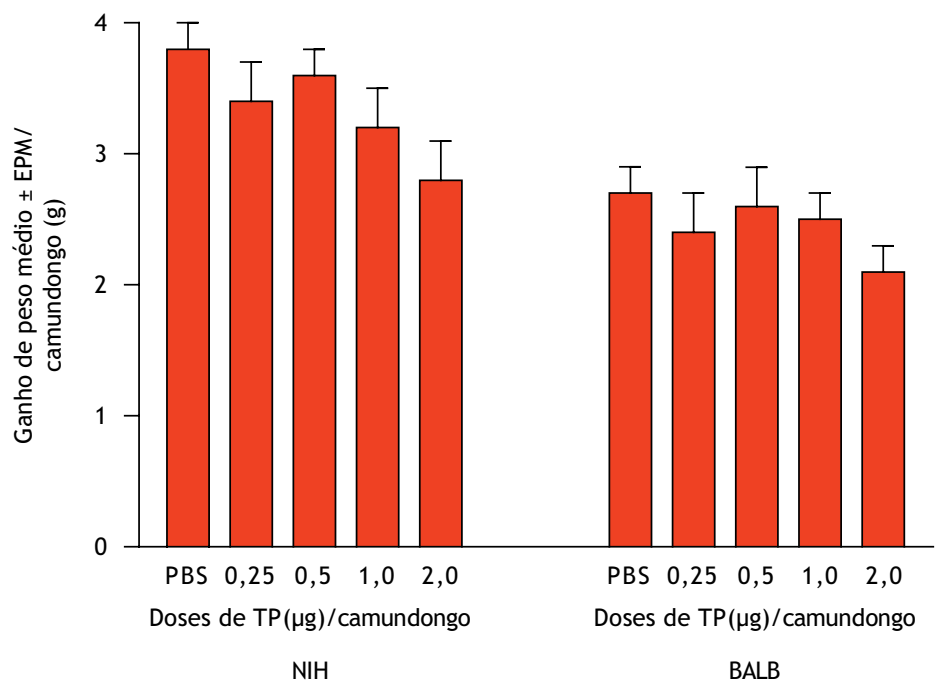

Fonte: Elaborada pelos autores, 2019.

Barras indicam o erro-padrão da média (EPM) do ganho de peso médio de dez animais.

Figura 2. Efeito da toxina pertussis (TP) no ganho de peso de camundongos NIH e BALB/cAn fêmeas, três dias após a inoculação intraperitoneal.

no TGPC em ambos os sexos e linhagens de camundongos. As Figuras 2 a 5 mostram que a TP inoculada por via ip, na faixa de doses de 0,25 a 2,0 $\mu \mathrm{g} /$ camundongo em ambas as linhagens e sexos, foi satisfatória no TGPC, já que o GPM dos camundongos $\mathrm{NIH}$ e BALB/cAn fêmeas (Figura 2) e machos (Figura 3) no $3^{\circ}$ dia, foram superiores ao inicial e, no $7^{\circ}$ dia, pelos critérios vigente e proposto, os percentuais de GPM dos camundongos tratados pela TP foram superiores a $60 \%$ ao do grupo-controle (PBS) para NIH e BALB/CAn fêmeas (Figura 4) e para NIH e BALB/CAn machos (Figura 5).
Os dados das Figuras 2 a 5 seguiram uma distribuição normal para ambas as linhagens $(p>0,1)$ e as variâncias não foram significativamente diferentes $(p>0,05)$. A partir da ANOVA, o tratamento com a TP, nas doses de 0,25 a 2,0 $\mu \mathrm{g} /$ camundongo nas linhagens $\mathrm{NIH}$ e BALB/cAn fêmeas (Figura 2) e machos (Figura 3), três dias após a inoculação, não interferiu no GPM em relação ao peso inicial ( $p$ > 0,05 e $p>0,1$, respectivamente), quando comparado ao GPM do grupo-controle PBS. Não houve diferença significativa no percentual de GPM sete dias após a inoculação de doses de TP de 0,25 a 2,0 $\mu \mathrm{g} /$ camundongo em relação ao controle (PBS) em fêmeas NIH $(p>0,1)$ 


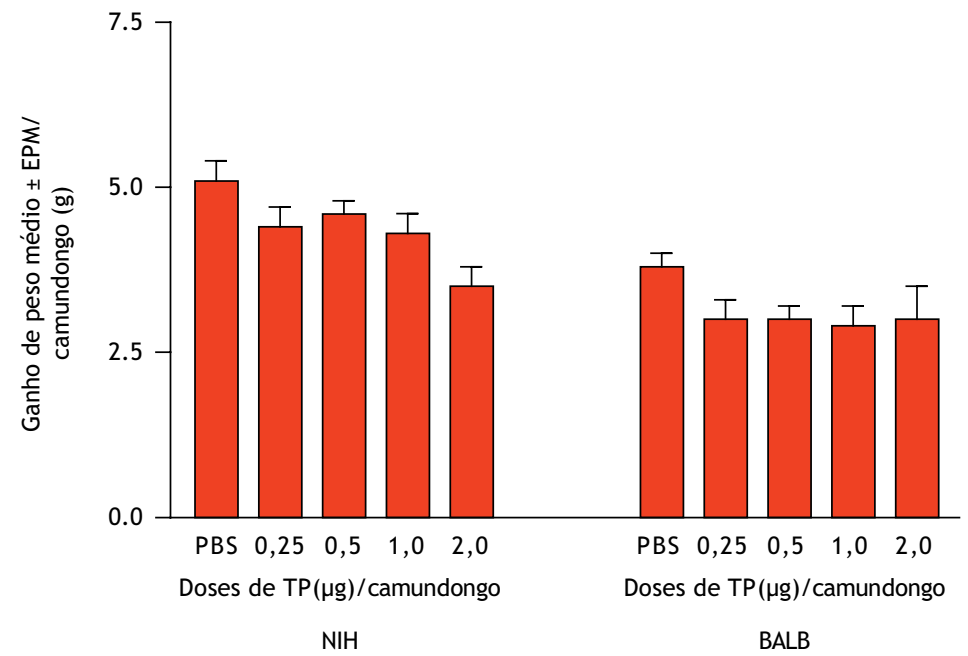

Fonte: Elaborada pelos autores, 2019.

Barras indicam o erro-padrão da média (EPM) do ganho de peso médio de dez animais.

Figura 3. Efeito da toxina pertussis (TP) no ganho de peso de camundongos NIH e BALB/cAn machos, três dias após a inoculação intraperitoneal.

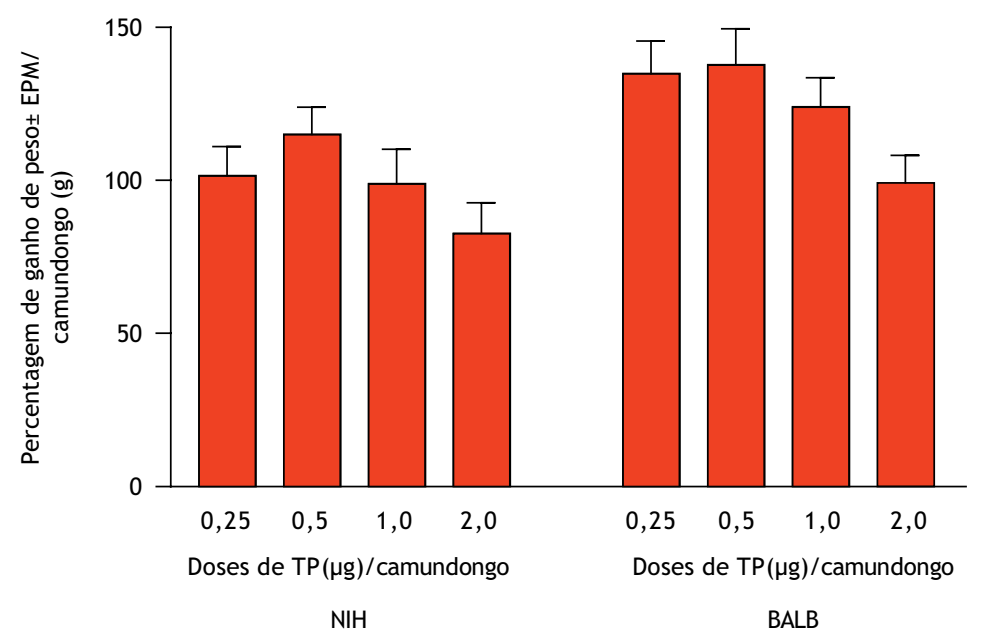

Fonte: Elaborada pelos autores, 2019.

Barras indicam o erro-padrão da média (EPM) do percentual de ganho de peso médio de dez animais.

Figura 4. Efeito da toxina pertussis (TP) na percentagem de ganho de peso de camundongos NIH e BALB/cAn fêmeas em relação ao controle, sete dias após a inoculação intraperitoneal.

e em fêmeas BALB/cAn $(p=0,05)$, como mostrado na Figura 4, bem como para os machos da linhagem BALB/cAn ( $p>0,05)$ (Figura 5$)$.

Os camundongos NIH machos (Figura 5) foram os mais sensíveis aos efeitos da TP, sete dias após a sua administração, com uma percentagem de GPM em relação ao controle inferior na dose de $2 \mu \mathrm{g} /$ camundongo, quando comparada às doses de 0,25 e 0,5 $\mu \mathrm{g}$ $(\mathrm{p}<0,001)$ e à dose de $1 \mu \mathrm{g} /$ camundongo $(\mathrm{p}<0,05)$.

Teste de ganho de peso em camundongos da vacina contra a difteria, o tétano e a pertussis

Não houve perda de peso dos animais-controle, de ambos os sexos e linhagens, três e sete dias após inoculação ip de solução fisiológica contendo $100 \mathrm{ppm}$ de timerosal, quando comparado ao peso inicial.
Os TGPC das vacinas DTP realizados em camundongos de ambos os sexos da linhagem NIH e em fêmeas BALB/cAn apresentaram resultados satisfatórios nas 36 amostras analisadas. Não ocorreram mortes no período do teste, o GPM no $3^{\circ}$ dia foi superior ao inicial e no $7^{\circ}$ dia, o valor médio (critério vigente) e o $L_{i}$ do IC95\% (critério proposto) para o percentual de GPM dos camundongos em relação ao controle foram superiores a $60 \%$. Os valores médios e IC $95 \%$ de percentagem de ganho de peso no $7^{\circ}$ dia variaram de $86,1 \%(60,8 \%-111,4 \%)$ a $133,9 \%(120,1 \%-147,7 \%)$ em NIH fêmeas; $77,3 \%(69,3 \%-85,3 \%)$ a $147,4 \%(138,4 \%-156,4 \%)$ em NIH machos e variaram de $73,6 \%(61,3 \%-85,9 \%)$ a $160,6 \%$ (151,2\%-170,0\%) em BALB/cAn fêmeas.

Diferentemente do resultado satisfatório do TGPC de 100\% das amostras de vacinas DTP em camundongos NIH de ambos os sexos 


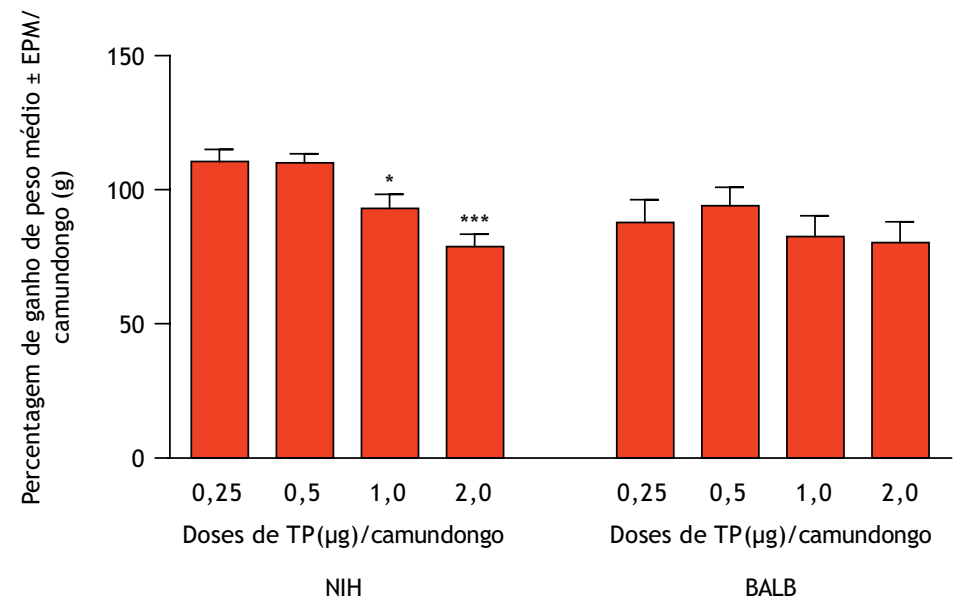

Fonte: Elaborada pelos autores, 2019.

Barras indicam o erro-padrão da média (EPM) do percentual de ganho de peso médio de dez animais.

* diferença significativa $(p<0,05)$ em relação à dose de $2 \mu \mathrm{g} /$ camundongo; *** diferença extremamente significativa $(p<0,001)$ em relação às doses de 0,25 e $0,5 \mu \mathrm{g} /$ camundongo pela ANOVA seguida do teste de comparações múltiplas de Dunnett.

Figura 5. Efeito da toxina pertussis (TP) na percentagem de ganho de peso de camundongos NIH e BALB/cAn machos em relação ao controle, sete dias após a inoculação intraperitoneal.

e em fêmeas BALB/cAn, em machos BALB/cAn, para duas (6\%) amostras de vacinas DTP, o TGPC foi insatisfatório pelo critério vigente no $7^{\circ}$ dia, com valores médios de percentagem de ganho de peso em relação ao controle de $57,0 \%$ (42,0\%-72,0\%) e $51,0 \%(27,7 \%-74,3 \%)$ inferiores a $60 \%$. Considerando-se o critério proposto para o $7^{\circ}$ dia, três amostras adicionais de vacinas DTP, correspondendo a $8,0 \%$ do total, seriam reprovadas em machos BALB/CAn, com os percentuais de GPM no $L_{i}$ do IC95\% menores do que $60 \%$ do controle, de $70,2 \%(40,7 \%-99,7 \%), 72,0 \%$ (55, $1 \%$ $88,9 \%)$ e $82,8 \%(55,5 \%-110,1 \%)$. Considerando-se, pois, ambos os critérios no $7^{\circ}$ dia, $14,0 \%$ das vacinas DTP seriam reprovadas no TGPC em machos BALB/cAn. Com relação aos dois outros critérios de conformidade no TGPC, todas as 36 amostras de vacinas DTP, não causaram mortes em camundongos machos BALB/cAn, bem como, perda de peso no $3^{\circ}$ dia após inoculação. As amostras satisfatórias em machos BALB/CAn no TGPC pelos critérios vigente e proposto apresentaram percentagens de GPM que variaram de $75,6 \%(65,8 \%-85,4 \%)$ a $155,4 \%(117,6 \%-193,2 \%)$.

Como o resultado insatisfatório da VPCI de referência no TGPC em machos BALB/CAn torna os camundongos desta linhagem e sexo inadequados para utilização no TGPC, os resultados insatisfatórios obtidos para as vacinas DTP não deveriam ser considerados.

\section{DISCUSSÃO}

Os camundongos $\mathrm{NIH}$ geneticamente variável e BALB/CAn geneticamente definido empregados nos TGPC foram submetidos ao monitoramento sanitário trimestral, como parte do sistema de garantia de qualidade realizado pelo ICTB da Fiocruz. Segundo a FELASA $^{19}$, é de vital importância que cada instituição estabeleça um programa de monitoramento de saúde dos animais, à medida que os pesquisadores necessitam de respostas mais confiáveis e seguras de seus experimentos ${ }^{21}$. Adicionalmente, quanto mais uniforme forem os animais utilizados em um teste, menor será o número necessário para atingirmos o padrão de exatidão ou de aceitabilidade $^{21}$, validade e reprodutibilidade ${ }^{22}$.

A validade do TGPC nas linhagens NIH e BALB/CAn, em machos e fêmeas, foi constatada pela não ocorrência de mortes e ausência de perda de peso dos animais do grupo-controle, no período de sete dias do teste. A partir do grupo-controle, observamos que o GPM das fêmeas, de ambas as linhagens, três dias após a inoculação do PBS, não foi significativamente diferente. No $7^{\circ}$ dia, o GPM das fêmeas NIH foi superior ao das fêmeas BALB/cAn. No caso dos animais machos, a diferença de comportamento de ganho de peso foi mais acentuada entre as linhagens após o $3^{\circ}$ e $7^{\circ}$ dias de teste, com o GPM em machos BALB/CAn cerca de 1,6 vez inferior aos dos machos da linhagem $\mathrm{NIH}$.

Segundo a $\mathrm{OMS}^{9}$, o crescimento monitorado no TGPC pode ser também afetado por outros fatores não relacionados à $\mathrm{VPCl}$, como: a linhagem de camundongos utilizada, as condições de alojamento e o status microbiológico destes animais. Por essa razão, camundongos-controle devem ser incluídos no teste e se uma VPCI de referência for usada os animais que recebem esta vacina são monitorados e devem ter pelo menos recuperado seu peso inicial no $3^{\circ}$ dia e no $7^{\circ}$ dia, o GPM por camundongo não deve ser inferior a $60 \%$ ao dos camundongos no grupo-controle. A validação e o estabelecimento do TGPC envolvem, pois, tanto a seleção da linhagem adequada como a determinação da reprodutibilidade dos testes, através da avaliação do ganho de peso no grupo-controle e no grupo da vacina de referência?.

A partir da $\mathrm{VPCl}$ de referência, confirmou-se que a linhagem de camundongos bem como o sexo influenciam o resultado do TGPC, como já constatado anteriormente em estudo interlaboratorial conduzido pelo National Institute for Public Health and the Environment ${ }^{18}$ na Holanda e na avaliação do Instituto Paul-Erlich dos dados obtidos do TGPC de vacinas DTP, realizado no Staatliches Serum Kontrollinstitut (SKIA) da Alemanha ${ }^{23}$. No SKIA, 
sob as mesmas condições de teste, camundongos NMRI mostraram um menor ganho de peso do que os camundongos ICR e a maioria das mortes ocorreu em camundongos ICR. No presente estudo, considerando o critério vigente no $7^{\circ}$ dia para aprovação no TGPC, os camundongos fêmeas das linhagens NIH e BALB/cAn e os machos NIH foram considerados mais apropriados do que os camundongos machos BALB/cAn na realização do TGPC. Porém, considerando o critério proposto ${ }^{20}$, o TGPC da VPCl de referência em NIH machos não seria satisfatório e, consequentemente, a linhagem e sexo em questão não adequados ao TGPC de vacinas DTP. $O$ emprego da VPCI de referência na escolha da linhagem e sexo de camundongos mais adequados a ser empregados no TGPC de vacinas DTP justifica-se, pois Hooker ${ }^{24}$, ao comparar vacinas DTP e DT com adjuvantes, mostrou que o baixo ganho de peso dos camundongos foi devido especificamente ao componente pertussis das vacinas e que um alto grau de padronização e reprodutibilidade no TGPC só podem ser alcançados intralaboratorialmente.

Além de Domingos ${ }^{20}$, WeiBer e Hechler ${ }^{23}$ recomendaram a incorporação do critério proposto no $7^{\circ}$ dia, ou seja, que o $L_{i}$ do IC95\% do GPM do grupo inoculado com as amostras, seja, no mínimo, $60 \%$ do GPM dos animais do grupo-controle. Esta modificação aumentaria os requisitos do TGPC de vacinas DTP, mas também forneceria uma definição clara e comparável do resultado associado a uma significância estatística. Segundo os autores ${ }^{23}$, se houver um alto grau de variabilidade ou se os resultados excederem somente levemente o mínimo requerido, não sendo assim os requerimentos cumpridos no primeiro teste, um segundo teste deve ser conduzido com o mesmo número de animais e os dados de ambos os testes devem ser usados para calcular o IC95\%. A possibilidade de um reteste também é preconizada pela $\mathrm{OMS}^{9}$ se a vacina DTP não satisfizer os critérios para sua aprovação no primeiro teste. Os dados de ambos os testes válidos devem ser combinados e os resultados finais calculados. A vacina não será aprovada se não cumprir os requerimentos do TGPC.

De acordo com Redhead e Seagroatt ${ }^{17}$, camundongos NIH fêmeas inoculados com a TP isolada ( 0,1125 e $0,45 \mu \mathrm{g} /$ camundongo) mostraram maior ganho de peso inicial do que os animais-controle inoculados com PBS no TGPC. Após o $4^{\circ}$ dia, os camundongos tratados com a TP ganharam peso em proporção igual ou superior ao do grupo-controle (PBS) e o peso final no $7^{\circ}$ dia dos animais inoculados com a TP foi superior ao do grupo-controle. Nossos resultados mostram que a TP $(0,25-2,0 \mu \mathrm{g} /$ animal $)$ inoculada em camundongos NIH e BALB/CAn de ambos os sexos foi também satisfatória no TGPC, não causando mortes, perda de peso no $3^{\circ}$ dia e com percentagem de GPM no $7^{\circ}$ dia em relação ao controle, superior a $60 \%$. Porém, diferentemente do observado por Redhead e Seagroatt ${ }^{17}$, a TP $(0,25$ a $2,0 \mu \mathrm{g} /$ camundongo $)$, em NIH e BALB/cAn de ambos os sexos, não causou no $3^{\circ}$ dia GPM superior ao do controle (PBS) e, no $7^{\circ}$ dia, o percentual de GPM em relação ao controle não diferiu para as quatro doses de TP para NIH fêmeas e BALB/CAn de ambos os sexos. Somente nos camundongos NIH machos, observou-se, na dose de $2 \mu \mathrm{g} /$ camundongo de TP, uma percentagem de GPM em relação ao controle inferior às doses de 0,25 e $0,5 \mu g(p<0,001)$ e à dose de $1 \mu \mathrm{g} /$ camundongo $(\mathrm{p}<0,05)$.
Resultados diferentes aos obtidos no presente estudo e por Redhead e Seagroatt ${ }^{17}$ foram observados por Gupta et al. ${ }^{25}$, que demonstraram que a TP causou perda de peso e mortalidade dose-dependente, no $3^{\circ}$ dia em diante, em camundongos das linhagens NIH e LACA, de ambos os sexos no TGPC. A TP acima de $0,4 \mu \mathrm{g} /$ dose/camundongo causou significante perda de peso em comparação com o grupo-controle, enquanto doses superiores a 0,75 $\mu \mathrm{g} /$ camundongo de TP mostraram aumentada mortalidade. Ambos os estudos ${ }^{17,25}$ mostraram que o LPS causa perda de peso dos animais no primeiro dia após inoculação, que decresceu quando o LPS foi administrado com a TP. A importância do TGPC na detecção de endotoxinas e TP foi demonstrada em três $\mathrm{VPCl}$, nas quais um alto conteúdo de endotoxinas resultou em grande perda de peso, em particular, nos dois primeiros dias, não passando a vacina pelo critério de ganho de peso no $3^{\circ} \mathrm{dia}^{26}$. As atividades promotoras de linfocitose e sensibilizante à histamina induzidas pela TP, entretanto, levaram à perda de peso do quarto dia em diante, fazendo com que o critério de ganho de peso no $7^{\circ}$ dia não fosse alcançado ${ }^{26}$.

Diferentemente do obtido neste trabalho, Horiuch et al. ${ }^{27}$ observaram que a dose de TP ( $2 \mu \mathrm{g} /$ camundongo) em camundongo fêmeas SLC levou a um ganho de peso no TGPC que excedeu ao do grupo-controle no período de observação de 11 dias.

Segundo a $\mathrm{OMS}^{28}$, em alguns países, um refinamento do TGPC é empregado pelos fabricantes no bulk final da VPCl. Camundongos são pesados individualmente imediatamente antes da inoculação, nos períodos de 16-24 h, 72 h e sete dias após a inoculação da VPCI. No dia 7, amostras sanguíneas são coletadas da veia da cauda e são contados os leucócitos. Considera-se a mudança de peso após 16-24 h, refletir a presença de LPS e um aumento de contagem de leucócitos, corresponder à presença de TP na vacina ${ }^{28}$. Testes para determinação de TP e LPS podem ser usados para monitorar e validar os métodos usados para a destoxificação da VPCl e podem também ser úteis na avaliação dos produtos finais ${ }^{28}$. No processo de validação dos procedimentos de fabricação, os fabricantes são estimulados a monitorar o conteúdo de TP e LPS na VPCl ${ }^{28}$. O teste in vitro, baseado no efeito clustering causado pela TP em células de ovário de hamster chinês ( $\mathrm{CHO}$ ), bem como o teste in vivo da atividade sensibilizante à histamina induzida pela TP podem ser usados para a determinação da TP na $\mathrm{VPCl}^{28}$. A concentração de endotoxina pode ser estimada preferencialmente pelo teste in vitro do lisado de amebócitos de Limulus (LAL). Embora não haja concordância em relação ao nível aceitável de endotoxina em $\mathrm{VPCl}$, a $\mathrm{OMS}^{28}$ recomenda aos fabricantes, a determinação da concentração de endotoxina, lote a lote, para monitorar a consistência da produção. 0 procedimento geral para realização do teste do LAL está descrito na Farmacopeia Brasileira ${ }^{29}$ e a sua adequação ao teste de VPCI foi publicada pela OMS9.

A partir de 2013, a OMS $^{9}$ passou a preconizar para as vacinas DTP, DTP combinadas, bem como para o bulk final da VPCl, o TGPC em combinação com o teste de promoção de leucocitose (TPL). Na $5^{a}$ edição da Farmacopeia Brasileira ${ }^{5}$, diferentemente da $6^{a}$ edição $0^{6}$, previa-se também para a vacina DTP adsorvida, a determinação do fator promotor de linfocitose ou TP, 
empregando-se como métodos apropriados a indução de linfocitose e as provas de atividade sensibilizadora da histamina em camundongos. Os procedimentos para a realização dos referidos testes estão descritos na publicação da $\mathrm{OMS}^{9}$. Além dos testes in vivo, do TPL e do teste de sensibilização à histamina realizados em camundongos para a determinação do conteúdo de TP ativa em $\mathrm{VPCl}$, a OMS 9 recomenda também o emprego do teste in vitro do efeito clustering em células $\mathrm{CHO}$ para a detecção de TP ativa em vacinas DTP e DTP combinadas. A vacina é considerada satisfatória quando contém $\leq 105 \mathrm{UI}$ de TP ativa por $0,5 \mathrm{~mL}$ de vacina. No entanto, o teste em células $\mathrm{CHO}$ não é um teste regulatório para a liberação de vacinas podendo ser usado para o monitoramento in house da consistência dos produtos ou para validação dos procedimentos de inativação?.

Algumas preparações de vacinas DTP podem causar ascite em camundongos no TGPC . Este acúmulo anormal de líquido na cavidade peritoneal não implicará em perda de peso, mas em ganho de peso corpóreo, em alguns casos, superior aos camundongos do grupo-controle, podendo atingir valores até $150 \%$ maiores. Entretanto, tais lotes de vacina não devem ser considerados satisfatórios no TGPC.

\section{CONCLUSÕES}

Os camundongos fêmeas de ambas as linhagens (NIH e BALB/CAn) mostraram-se adequados para a realização do TGPC de vacinas DTP, independentemente do critério de peso escolhido no $7^{\circ}$ dia.
Todas as 36 amostras de vacinas DTP testadas em camundongos fêmeas NIH e BALB/cAn foram satisfatórias no TGPC, independentemente do critério escolhido no $7^{\circ}$ dia.

Os camundongos machos BALB/cAn foram considerados impróprios para a realização do TGPC de vacinas DTP.

O TGPC, em ambas as linhagens e sexos, revelou baixa sensibilidade na detecção do efeito da TP isolada $(0,25$ a $2 \mu \mathrm{g} /$ camundongo), independentemente do critério de peso escolhido no $7^{\circ}$ dia.

A TP (0,25 a $2 \mu \mathrm{g} /$ camundongo) em NIH e BALB/cAn de ambos os sexos não interferiu no ganho de peso dos animais três dias após inoculação por via ip.

A TP $(0,25$ a $2 \mu \mathrm{g} /$ camundongo) em NIH fêmeas e BALB/cAn de ambos os sexos não alterou o ganho de peso dos animais sete dias após inoculação por via ip.

Os camundongos NIH machos foram os mais sensíveis aos efeitos de redução de ganho de peso corpóreo causados pela TP $(0,25$ a $2 \mu \mathrm{g}$ / camundongo) no $7^{\circ}$ dia após inoculação. Uma relação dose-efeito foi demonstrada com a faixa de doses empregada.

A adoção de novo critério de aprovação de vacina DTP no TGPC, baseado no valor do $L_{i}$ do IC95\% do GPM do grupo teste, como sendo igual ou maior a 60\% do GPM do grupo-controle, deve ser encorajado por aumentar a sensibilidade e a precisão do teste.

\section{REFERÊNCIAS}

1. World Health Organization - WHO. Pertussis vacines: WHO position paper: August 2015. Weekly Epidemiological Record. August 28, 2015[acesso 3 ago 2019]. Disponível em: http://www.who.int/wer

2. Ministério da Saúde (BR). Manual de vigilância epidemiológica de eventos adversos pósvacinação. 3a ed. Brasília: Ministério da Saúde; 2014[acesso 3 ago 2019]. Disponível em: http://bvsms.saude.gov.br/bvs/publicacoes/manual_ vigilancia_epidemiologica_eventos_adversos_pos_ vacinacao.pdf

3. Hodder SL, Mortimer Jr EA. Epidemiology of pertussis and reactions to pertussis vaccine. Epidemiol Rev. 1992;14(1):243-67. https://doi.org/10.1093/oxfordjournals.epirev.a036089

4. Cody CL, Baraff LJ, Cherry JD. Nature and rates of adverse reactions associated with DTP and DT immunizations in infants and children. Pediatrics. 1981;68(5):650-60. PMID: 7031583

5. Agência Nacional de Vigilância Sanitária Anvisa. Farmacopeia Brasileira. 5a ed. Brasília: Agência Nacional de Vigilância Sanitária; 2010[acesso 1 set 2019]. Disponível em: http://portal.anvisa.gov.br/documents/33832/26
0079/5\%C2\%AA+edi\%C3\%A7\%C3\%A30+-+Volume+2/ ce7e36ca-b3f4-46eb-9a99-2974c4041383

6. Agência Nacional de Vigilância Sanitária Anvisa. Farmacopeia Brasileira. 6a ed. Brasília: Agência Nacional de Vigilância Sanitária; 2019[acesso 1 set 2019]. V. 2: Monografias Produtos Biológicos, p. 142-55. Disponível em: http://portal.anvisa.gov.br/documents/33832/259143/ Produtos+Biol\%C3\%B3gicos+Pronto.pdf/ daec6b9b-8465-4b39-8f3d-0c1b5a5d3177

7. European Pharmacopoeia Commission. Diphtheria, tetanus and pertussis (whole cell) vaccine (adsorbed). In: European Pharmacopoeia Commission. European Pharmacopoeia. 8a ed. Paris: European Directorate for the Quality of Medicines \& HealthCare; 2013. p. 827-8.

8. British Pharmacopoeia Comission. Diphtheria, tetanus and pertussis (whole cell) vaccine (adsorbed). In: British Pharmacopoeia Comission. British Pharmacopoeia. London: Health Minister; 2017. p. IV580-1.

9. World Health Organization - WHO. Manual for quality control of diphtheria, tetanus and pertussis vaccines. Geneva: World Health Organization; 2013[acesso 5 ago 2019]. Disponível em: http://www.who.int/ vaccines-documents 
10. Cohen H, Ramshorst JD, Drion EF. Relation between toxicity tests in mice and reactions in children using four lots of quadruple vaccine (DTP-polio). In: Proceedings of 21st International Symposium; London, United Kingdon. Washington: International Association of Microbiological Societies Permanent Section of Microbiological Standardization; 1969[acesso 11 ago 2019]. Disponível em: https://www.karger.com/Book/Toc/217536

11. Butler NR, Voyce MA, Burland WL, Hilton ML. Advantages of aluminium hydroxide adsorbed combined diphtheria, tetanus, and pertussis vaccine for the immunisation of infants. Br Med J. 1969;1:663-6. https://doi.org/10.1136/bmj.1.5645.663

12. Hilton ML, Wurland WL. Pertussis-containing vaccines: the relationship between laboratory toxicity tests and reactions in children. In: Proceedings of 25th International Symposium; Bilthoven, United Kingdon. Washington: International Association of Microbiological Societies Permanent Section of Microbiological Standardization; 1970[acesso 11 ago 2019]. Disponível em: https://www.karger.com/Book/Home/217540

13. Perkins FT, Sheffield F, Miller CL, Skegg JL. The comparison of toxicity of pertussis vaccines in children and mice. In: Proceedings of 25th International Symposium; Bilthoven, UK. Washington: International Association of Microbiological Societies Permanent Section of Microbiological Standardization; 1970[acesso 11 ago 2019]. Disponível em: https://www.karger.com/Book/Home/217540

14. Pittman M, Furmam BL, Wardlaw AC. Bordetella pertussis: respiratory tract infection in the mouse: pathophysiological responses. J Infect Dis. 1980;142(1):56-66. https://doi.org/10.1093/infdis/142.1.56

15. Vuolo AM, Lustigman B. Assay of pertussis vaccine reactivity factors by measurement of the paw swelling response, endotoxin and histamine sensibilizing factor. Biologicals. 1993;21(1):45-52. https://doi.org/10.1006/boil.1993.1045

16. Baraff LJ, Manclark CR, Cherry JD, Christenson P, Marcy SM. Analysis of adverse reactions to diphteria and tetanus toxoids and pertussis vaccine by vaccine lot, endotoxin content, pertussis vaccine potency and percentage of mouse weight gain. Pediatr Infect Dis J.1989;8(8):502-7. https: //doi.org/10.1097/00006454-198908000-00006

17. Redhead K, Seagroatt V. The effects of purified components of Bordetella pertussis in the weight gain test for the toxicity testing of pertussis vaccines. J Biol Stand. 1986;14(1):57-65. https://doi.org/10.1016/50092-1157(86)80009-9

18. Kapelle IS, Gun JW, Marsman FR, Hendriksen CFM, Donk HJM. Collaborative study on test systems to assess toxicity of whole cell pertussis vaccine. Biologicals. 1997;25(1):41-57. https://doi.org/10.1006/biol.1996.0059
19. Nicklas W, Baneux P, Boot R, Decelle T, Deeny AA, Fumanelli $M$ et al. Recommendations for the health monitoring of rodent and rabbit colonies in breeding and experimental units. Lab Anim. 2002;36(1):20-42. https: / /doi.org/10.1258/0023677021911740

20. Domingos RM. Avaliação do ensaio de ganho de peso corpóreo em camundongos no controle de qualidade da vacina tríplice bacteriana DTP, RJ [dissertação]. Rio de Janeiro: Fundação Oswaldo Cruz; 2006.

21. Andrade A, Pinto SR, Oliveira RS. Animais de laboratório: criação e experimentação. 2a ed. Rio de Janeiro: Fundação Oswaldo Cruz; 2006.

22. Mähler M, Berard M, Feinstein R, Gallagher A, Illgen-Wilcke $B$, Pritchett-Corning $K$ et al. FELASA recommendations for the health monitoring of mouse, rat, hamster, guinea pig and rabbit colonies in breeding and experimental units. Lab Anim. 2014;48(3):178-92. https://doi.org/10.1177/0023677213516312

23. Weißer K, Hechler U. Animal welfare aspects in the quality control of immunobiologicals: a critical evaluation of the animal tests in pharmacopoeial monographs. Nottingham: Frame; 1997.

24. Hooker JM. A laboratory study of some difteria-tetanus-pertussis vacines.

J Biol Stand. 1981;9(4):493-506. https://doi.org/10.1016/S0092-1157(81)80042-X

25. Gupta RK, Saxena SN, Sharma SB, Ahuja S. The effects of purified components and lipopolysaccharide on the results of the mouse weight gain test. J Biol Stand. 1988;16(4):321-31. https://doi.org/10.1016/0092-1157(88)90020-0

26. Kurokawa M. On toxicity testing. In: Proceedings of 25th International Symposium; Bilthoven, United Kingdon. Washington: International Association of Microbiological Societies Permanent Section of Microbiological Standardization; 1970[acesso 11 set 2019]. Disponível em: https://www.karger.com/Book/Home/217540

27. Horiuch Y, Takahashi M, Asada S, Ishida S. Increased levels of active pertussis toxin may aid a pertussis vaccine to pass the mouse body weight gain test. Biologicals. 1994:22(3):243-8. https://doi.org/10.1006/biol.1994.1035

28. World Health Organization - WHO. Recommendation for whole cell pertussis vaccine. Geneva: World Health Organization; 2007[acesso 1 set 2019]. Disponível em: https://www.who.int/biologicals/publications/trs/areas/ vaccines/whole_cell_pertussis/Annex\%206\%20whole\%20 cell\%20pertussis.pdf?ua=1

29. Agência Nacional de Vigilância Sanitária Anvisa. Farmacopéia Brasileira. 6a ed. Brasília: Anvisa; 2019 [acesso 1 set 2019]. v. 1: Métodos biológicos, testes biológicos e microbiológico, p. 380-7. Disponível em: http://portal.anvisa.gov. br/documents/33832/259143/Volume+1+Pronto. pdf/4ff0dfe8-8a1d-46b9-84f7-7fa9673e1ee1 
Agradecimentos

O presente trabalho foi realizado com o apoio da Coordenação de Aperfeiçoamento de Pessoal de Nível Superior Brasil (CAPES), Código de Financiamento 001.

Contribuição dos Autores

Domingos RM, Miller RA - Concepção, planejamento (desenho do estudo), aquisição, análise, interpretação dos dados e redação do trabalho. Corrado AP, Zamith HPS - Concepção, planejamento (desenho do estudo) e redação do trabalho. Todos os autores aprovaram a versão final do trabalho.

Conflito de Interesse

Os autores informam não haver qualquer potencial conflito de interesse com pares e instituições, políticos ou financeiros deste estudo.

Licença CC BY-NC atribuição não comercial. Com essa licença é permitido acessar, baixar (download), copiar, imprimir, compartilhar, reutilizar e distribuir os artigos, desde que para uso não comercial e com a citação da fonte, conferindo os devidos créditos de autoria e menção à Visa em Debate. Nesses casos, nenhuma permissão é necessária por parte dos autores ou dos editores. 